\title{
CULTURA ESCRITA E ESCOLARIZAÇÃO: PARTICIPAÇÃO E AMPLIAÇÃO DOS USOS SOCIAIS DA ESCRITA POR SUJEITOS ORIUNDOS DE UM PROGRAMA DE CORREÇÃO DE FLUXO
}

\author{
WRITING CULTURE AND SCHOOLING: \\ PARTICIPATION AND EXTENSION OF THE SOCIAL USE OF THE WRITING BY \\ SUBJECTS OF A FLOW CORRECTION PROGRAM
}

Priscila de Sousa ${ }^{1}$

\begin{abstract}
Resumo: O tema deste estudo é a ampliação dos usos sociais da escrita por alunos oriundos de um programa de correção de fluxo. Tendo como fundamentação teórica os Estudos do Letramento, a pesquisa objetiva descrever analiticamente um processo de ensino escolar desenvolvido a partir de um projeto de letramento. Busca formas de empreender um processo escolar que promova participação em eventos de letramento, ampliação das práticas de letramento e imersão na cultura escrita. As compreensões provenientes desta pesquisa repercutiram no desenvolvimento de ações movidas pelo compromisso de contribuir para o processo de imersão dos alunos na cultura escrita.
\end{abstract}

Palavras-chave: Letramento; Correção de fluxo; Projeto de letramento; Língua Portuguesa.

Abstract: The subject of the study is the expansion of the social uses of writing by students from a flow correction program. It has a theoretical foundation of the Studies of Literacy and is moved by the objective to describe analytically the process of school education developed from a literacy project. It looks for ways to undertake a school process that promotes participation in literacy events, amplification of literacy practices and immersion in written culture. The insights derived from this research had repercussions in the development of actions motivated by the commitment to contribute to the process of immersion of the students in the written culture.

Keywords: Literacy; Flow correction; Literacy project; Portuguese language.

\section{Introdução}

Este estudo situa-se na área de concentração Linguagens e Letramentos e na linha de pesquisa Leitura e Produção Textual: diversidade social e práticas docentes, inserindo-se nas atividades do Mestrado Profissional em Letras - PROFLETRAS da Universidade Federal de Santa Catarina (UFSC). Refere-se a uma pesquisa que tem como objeto a imersão na cultura

\footnotetext{
${ }^{1}$ Mestre em Letras, professora de Língua Portuguesa da Secretaria Estadual de Educação de Santa Catarina e articuladora da área de Linguagens na Rede Marista Solidariedade.
} 
escrita por alunos de $1^{\circ}$ ano de Ensino Médio oriundos do Programa de Correção do Fluxo idade/série: recuperação dos saberes e a continuidade escolar de seus percursos formativos.

O referido programa tinha como principais objetivos equiparar idade/série de $100 \%$ dos estudantes do Ensino Fundamental, além de permitir o ingresso no Ensino Médio com condições de permanência e aproveitamento a esses mesmos estudantes.

Passados quatro anos de implantação do programa, apesar de terem avançado para o Ensino Médio por meio da aprovação automática, boa parte dos estudantes apresentou dificuldades para permanecer no Ensino Médio, o que era a proposta inicial do programa.

A partir do reconhecimento da persistência da situação de evasão escolar e repetência dos alunos egressos desse programa, cabe não apenas questionar sua eficácia para além da esfera institucional, mas também agir de modo a planejar uma ação escolar comprometida com a imersão desses sujeitos na cultura escrita.

À luz dessa contextualização, a questão geral de pesquisa que norteia o delineamento deste estudo assim se enuncia: Como empreender um processo de caráter escolar que faculte participação em eventos de letramento e, a ampliação das práticas de letramento e imersão na cultura escrita por alunos oriundos de um programa de correção de fluxo?

Visando a contribuição em relação a tal problema, este artigo conta com três seções de conteúdo. Na primeira, discutiremos brevemente a fundamentação teórica que subsidia este estudo: a díade conceitual eventos e práticas de letramento; os modelos de letramento e os letramentos dominantes e vernaculares, refletindo acerca das implicações desses conceitos para o ensino escolar. Na sequência, descrevemos a metodologia empregada no desenvolvimento do projeto de pesquisa, bem como a lógica interna do planejamento das ações. Na terceira e última seção de conteúdo, passamos a responder a questão de pesquisa que move esta análise, apresentando a discussão dos dados gerados, e, por fim, as considerações finais.

\section{Estudos do letramento: conceituação, relações e implicações}

O termo letramento ganhou espaço no Brasil a partir da década de 1980, com os estudos de Mary Kato, quando era ainda vinculado a níveis expressivos de escolarização e aos usos da escrita eram atrelados à erudição. O termo passou a ter outro significado também no Brasil com o surgimento dos Novos Estudos do Letramento (NLS) no Reino Unido e nos Estados Unidos, onde até então se usava o termo para nomear a condição de quem era letrado, no sentido de ler

Para Barton (1994), o letramento é um fenômeno que está incorporado às atividades da vida diária das pessoas; não é, portanto, algo restrito ao cotidiano escolar. Pelo contrário, ele 
transcende esses espaços e se dá, recorrentemente, de variadas formas e com vários significados.

Assim, é complexa a tarefa de definir o conceito de letramento de modo a abarcar todas as instâncias em que ele se manifesta e do qual é parte. Para isso, Barton reflete sobre a necessidade de criação de uma metáfora na tentativa de destacar a dimensão social do fenômeno do letramento. Dessa forma, o autor propõe a metáfora da ecologia como uma tentativa de abranger a complexidade do fenômeno do letramento.

A metáfora proposta por Barton (1994) tem implicada a ideia de que os atos de ler e escrever não existem independentemente, mas atendem a objetivos sociais. Desse modo, diversos fatores sociais inter-relacionados sustentam a sobrevivência de determinados atos de ler e escrever e esses atos estão relacionados a "nichos ecológicos" específicos.

Barton (1994) afirma que o letramento não se resume ao aprendizado formal da escrita, mas também compreende os usos sociais que as pessoas fazem dela, conforme as atividades que desempenham e as demandas de suas vidas diárias.

Desse modo, é importante atentar para o fato de que, mesmo que um indivíduo nunca tenha entrado em uma sala de aula, é provável que, em alguma medida, ele lide com textos escritos em seu cotidiano e, consequentemente, participe de eventos de letramento.

\subsection{Práticas e eventos de letramento: concepções sociais da leitura e da escrita}

Nomeados pela primeira vez pela etnógrafa Shirley Brice Heath, segundo Barton (1994, p. 35), o conceito de eventos de letramento tem suas raízes na ideia de eventos de fala da Sociolinguística e corresponde, basicamente, às atividades desempenhadas regularmente pelos seres humanos em que a escrita esteja presente.

Já as práticas de letramento, termo cunhado por Street (1984), podem ser entendidas como formas culturais de fazer uso da escrita nesses mesmos eventos. Ambos os conceitos são nomeados no plural porque as valorações sociais inerentes aos usos da escrita variam conforme os grupos sociais, as culturas e as instituições.

Enquanto determinados eventos estão relacionados a situações mais formais e atendem às necessidades de instituições sociais, como a escola e o local de trabalho, por exemplo, outros eventos são comuns em situações mais informais, relacionadas à esfera doméstica e à vida cotidiana.

Hamilton (2000), na tentativa de distinguir eventos e práticas de letramento, propõe a metáfora do iceberg na tentativa de distinguir eventos e práticas de letramento. Conforme a 
autora, os eventos são a ponta do iceberg, sua parte visível. Deles é possível inferir as práticas dos sujeitos envolvidos, que constituiriam a base submersa do iceberg. Segundo essa perspectiva, um mesmo evento de letramento pode ter significados diferentes e ser valorizado de diferentes modos conforme os participantes envolvidos.

Enquanto os eventos são momentos pontuais, visíveis, fotografáveis e recorrentes de uso da língua escrita, as práticas de letramento envolvem os valores e as ideologias subjacentes à participação nesses eventos, ou seja, os diferentes modos pelos quais as diversas culturas lidam com tais eventos e, portanto, distanciam-se do contexto imediato em que os eventos ocorrem.

Essa díade conceitual nos é cara, em se tratando deste estudo, pois a partir dela é possível assumir um modelo analítico capaz de levar à depreensão de quando, onde e que tipo de artefatos os sujeitos leem, escrevem, dialogam sobre textos escritos, enfim, interagem por meio da escrita e têm compreensões distintas a respeito dessas mesmas

É importante reconhecer que as pessoas constituem-se por diferentes práticas de letramento, as quais se desenvolvem em articulação aos eventos de letramento, e que muitas dessas práticas destoam do que é esperado e valorizado pelas instâncias culturais dominantes. Tal complexidade nos remete aos modelos autônomo e ideológico de letramento, objetos da seção seguinte.

\subsection{Modelos de letramento: perspectivas ideológicas acerca dos usos da escrita}

No que se refere às discussões acerca do fenômeno do letramento, vale destacar ainda um par conceitual proposto pelo antropólogo Brian Street (1984): os conceitos de modelo autônomo e modelo ideológico de letramento.

O modelo autônomo de letramento caracteriza-se pela dissociação das dimensões social e política das práticas de leitura e escrita. Além disso, de acordo com essa perspectiva, acreditase que as funções da linguagem sejam determinadas pelo domínio da escrita, especialmente as funções lógicas. Assim, a oralidade seria algo secundário, ligado apenas às funções interpessoais da linguagem, enquanto a escrita exigiria a capacidade cognitiva de abstrair e seria, portanto, mais complexa.

Enquanto atribui à técnica da escrita em si mesma a responsabilidade sobre o desenvolvimento das habilidades cognitivas e competências individuais, o modelo autônomo de letramento torna-se, na sua essência, ideológico, uma vez que, como afirma Street (2003, p. 6), esforça-se por dar à escrita uma conformação de técnica, descolada de seu uso efetivo. 
Além disso, o modelo em tela desconsidera as particularidades dos sujeitos que usam a escrita, na medida em que assume que, após dominado o sistema alfabético, todos teriam iguais condições de utilizar a escrita e o fariam para diferentes finalidades independentemente do aprendido. Essa separação desencadeia concepções errôneas relacionadas à neutralidade do ensino e à concepção de leitura e escrita como sistemas independentes e fechados.

Segundo o modelo ideológico de letramento, a escola é um espaço de variação e mudança, e não de neutralidade e uniformidade, como prevê o modelo autônomo. Portanto, as habilidades técnicas e o conhecimento sistematizado não retiram do letramento as suas implicações ideológicas. Levar em conta uma escola heterogênea implica considerar os entornos socioculturais a que pertencem os alunos, que se distinguem por formas diversas de uso e valoração da escrita.

Considerar o modelo ideológico de letramento implica minimizar a concepção autônoma, homogênea e tecnicista característica do modelo autônomo de letramento e reconhecer a dimensão política e ideológica inerente aos diferentes modos pelos quais as sociedades fazem uso da escrita.

Por fim, cabe destacar que os modelos autônomo e ideológico de letramento não estão em polos opostos, mas estabelecem relação de conteúdo/continente; ou seja, o termo modelo ideológico de letramento não foi cunhado numa tentativa de negação do acesso aos bens culturais, mas sim como uma tentativa de entender a lógica dos usos sociais da escrita nas diferentes culturas, o que permite a imersão na cultura escrita.

\subsection{Letramento dominantes e vernaculares: relações de constitutividade e tensão}

É reconhecida a existência de formas diversas de uso da escrita nos Estudos do Letramento, que variam conforme mudanças espaciais, temporais e relações de poder nas diferentes culturas. Barton, Hamilton e Ivanic (2000) defendem que o letramento é algo situado. Sob essa ótica, o letramento é encarado como um conjunto de práticas sociais, passíveis de depreensão a partir de eventos, em que as relações interpessoais são mediadas por textos escritos.

Por isso, há certa tensão entre os usos do plano do cotidiano, mais familiares, e os usos restritos a um grupo ou instituição específicos. M. Hamilton, em seus estudos, afirma que existem os letramentos dominantes e os letramentos vernaculares. 
No entendimento de Barton e Hamilton (1998), os letramentos dominantes estão associados a instituições formais, como escola, igreja, local de trabalho, organizações nas quais estão previstos agentes como, por exemplo, professores, líderes religiosos, especialistas etc.

Já os letramentos vernaculares são aqueles que não passaram por processos de regulamentação ou sistematização. Portanto, não são regidos por regras ou procedimentos formais de instituições sociais, mas têm sua origem nas demandas cotidianas.

Assim, os letramentos vernaculares são fruto da criatividade humana, capaz de gerar novas práticas de letramento improvisadas e espontâneas. Segundo Barton, Hamilton e Ivanic (2000), as diferentes práticas de letramento costumam ser padronizadas por instituições sociais e sofrem influência maior das relações de poder. Assim, alguns letramentos são dominantes e por isso gozam de mais visibilidade e influência do que outros. No entanto, é importante considerar que letramentos dominantes e vernaculares não são independentes e separados por categorias de atividade. Ao contrário, eles mantêm diálogo e as fronteiras que os determinam são permeáveis e passíveis de mudanças.

Street (2003) reflete acerca dos letramentos vernaculares $e$ dominantes, revelando as inerentes tensões existentes nas relações entre esses universos. Desse modo, é preciso considerar a complexidade dessas relações e é a partir delas que o autor propõe a hibridização entre o que é local e o que é global. Segundo B. Street, o que é global não chega intacto ao local, já que nesse percurso há novas formas e valorações que o transformam.

É importante identificar, porém, a linha tênue existente entre o respeito aos letramentos vernaculares e a romantização desses letramentos. Isolar as práticas locais na tentativa de mantê-las intactas, já que elas, por si mesmas, atendem às necessidades imediatas da comunidade, parece ir de encontro à democratização dos bens culturais para sujeitos inseridos em uma comunidade global.

Assim, a relação entre local e global não deve ser excludente, mas articulada. Os usos da escrita só podem ser locais porque sempre estão situados no tempo e no espaço. O global se imbrica ao local na medida em que essas comunidades tencionam garantir seus direitos e necessidades locais. Nessa perspectiva, uma pedagogia culturalmente sensível dirige-se a uma prática de ensino e de aprendizagem situada (BARTON; HAMILTON; IVANIC, 2000), em que a escrita por si mesma não é capaz de resolver problemas inerentes à prática social.

É essencial considerar a centralidade do letramento escolar, já que a escola é, nesse modo de organização social, a principal agência de letramento (KLEIMAN, 2001 [1995]), responsável pela inserção formal dos sujeitos na cultura escrita, por meio de suas ações 
educativas, especialmente em determinados contextos socioeconômicos. Segundo a perspectiva do modelo ideológico de letramento, essa inserção deve acontecer considerando a formação histórica e social dos alunos.

Ainda que a escola precise se reorganizar para atender a essas necessidades, é possível desenvolver práticas pedagógicas teoricamente ancoradas mesmo dentro das configurações encontradas atualmente. Essa possibilidade pode estar materializada na organização de projetos de letramento.

\section{Caminhos para a realização deste estudo}

A caracterização adotada para desenvolver este estudo aproxima-se da pesquisa-ação, já que é um trabalho centrado na realidade escolar, envolvendo sua comunidade, com vistas a uma transformação. Neste estudo, especificamente, tanto a escolha dos participantes - alunos egressos de uma turma de correção de fluxo idade-série - quanto o planejamento dos encontros e sua efetiva implementação se deram considerando a participação dos sujeitos envolvidos direta ou indiretamente na pesquisa: direção, corpo docente, professora-pesquisadora e estudantes.

Para a realização desta pesquisa, optamos por trabalhar com uma escola estadual situada em entorno de flagrante vulnerabilidade social em razão de nossa vontade política de refletir sobre o papel da escola como principal agência de letramento (KLEIMAN, 2001 [1995]) nesses espaços sociais e na tentativa de colaborar para a reflexão dos processos de ensino ali levados a termo.

Em consonância com outros estados brasileiros, no ano de 2012, a Secretaria de Estado da Educação de Santa Catarina lançou o Programa de Correção do Fluxo idade/série: recuperação dos saberes. Nessa proposta, foram apresentados como principais objetivos corrigir o fluxo idade/série de 100\% dos estudantes do Ensino Fundamental, além de permitir ingresso no Ensino Médio com condições de permanência e aproveitamento.

Em 2012, setenta e sete alunos divididos em quatro turmas atendidas por duas professoras admitidas em caráter temporário estavam matriculados no programa de correção de fluxo na escola em que a pesquisa foi realizada. Em 2015, 53 deles não estavam mais matriculados na escola, 13 frequentavam o $1^{\circ}$ ano do Ensino Médio, quatro estavam no $2^{\circ}$ ano e apenas quatro alunos completaram o Ensino Médio sem que houvesse repetência. 
Os estudantes participantes da pesquisa são alunos pertencentes ao primeiro ano do Ensino Médio, que, em 2012, foram promovidos para o Ensino Médio pelo Programa de Correção de Fluxo: recuperação do saberes e, desde então, não alcançaram aproveitamento condizente com a aprovação.

Para o desenvolvimento de nossos encontros, escolhemos como encaminhamento metodológico para o projeto de letramento (KLEIMAN, 2000). Essa perspectiva diferencia-se de uma concepção tradicional de ensino que costuma encarar a aprendizagem de leitura e produção textual como a aprendizagem de competências e habilidades individuais, já que tem como ponto de partida a prática social. É ela quem oferece os parâmetros da ação coletiva, das atividades de leitura e escrita, do (re)planejamento em função dos objetivos compartilhados e das metas a seguir.

A adoção da prática social como princípio organizador do ensino traz consigo a necessidade de identificar práticas significativas, considerando os interesses da comunidade. Essa atividade pressupõe um envolvimento com bagagem repertório cultural dos alunos, que, para além da sala de aula, já participam de eventos de letramento.

Os textos lidos e escritos no bojo de um projeto de letramento têm produção e circulação reais. São trazidos para a sala de aula e dela são levados para subsidiar ações que serão realizadas, em geral, fora do ambiente escolar.

Desse modo, é possível enxergar nos projetos de letramento um modo significativo de conciliar os conteúdos com os quais a escola precisa trabalhar e a prática social da qual os alunos tomam parte, bem como dar ao professor mais autonomia no planejamento das unidades de ensino e na escolha de materiais didáticos.

Essa maneira diferente de encarar o trabalho do professor confere autonomia maior à atividade docente. Cabe salientar que o professor que escolhe trabalhar com projetos de letramento não ficará necessariamente à mercê do interesse dos alunos e abrirá mão de ensinar os conhecimentos historicamente acumulados considerados globais.

\section{Caminhos para a implementação de um projeto de letramento: articulação entre os universos local e global}

Na tentativa de implementação do projeto de letramento, encontramos algumas questões de natureza institucional que, ainda que não tenham sido determinantes na consecução da pesquisa, configuraram-se como condições diretas impostas ao alcance dos objetivos propostos. 
A principal delas é a carência de estrutura propícia para o trabalho dos professores: espaço de estudos, recursos didáticos, sinal de internet e materiais diversos.

Também cabe sinalizarmos para constrições de ordem antropológica, como a dificuldade para garantir presença/engajamento dos alunos nas aulas, bem como suas recorrentes falta.

Refletindo acerca dessa situação, é importante considerar que, ao longo da história da sua escolarização, esses alunos não participaram de modo geral de vivências escolares que contribuíssem efetivamente para o desenvolvimento de práticas de letramento que suportem participação consequente em um evento de letramento escolar, a exemplo da aula.

A partir dos depoimentos dos participantes, é possível inferir que o Programa de Correção do Fluxo idade/série: recuperação dos saberes era constituído de propostas pedagógicas ocupadas com o atendimento às diferenças individuais, à adequação do currículo e, consequentemente, às alternativas metodológicas, sem alterar, contudo, velhas estruturas. Práticas como essa têm ocultado o fenômeno social da exclusão escolar, centrando os problemas educacionais apenas nos recursos pedagógicos e nos problemas pontuais e práticos dos alunos.

A partir da breve problematização das constrições a que o delineamento e a consecução do projeto de letramento em tela estavam submetidos, é possível reconhecer os limites que se interpõem não apenas nesta situação especificamente, mas na realidade de boa parte das escolas situadas em entornos de vulnerabilidade social. É necessário, porém, reiterar que encaramos as dificuldades encontradas como situações que interferiram no andamento do projeto de letramento levado a termo no bojo deste estudo, mas de modo algum o inviabilizaram.

Tendo presente essas questões, propusemos este projeto de letramento, cujo enfoque residiu na ampliação dos usos sociais da escrita pela reflexão sobre a relação entre sociedade, natureza e Homem. Ou seja, o trabalho problematizou o sujeito com o outro na sociedade, modificando a natureza, compreensão, a nosso ver, fundamental para a desejada ruptura com o processo de alienação.

A problemática em foco partiu do tratamento dado ao tempo na contemporaneidade, seguindo pela mudança de hábitos (inclusive alimentares), justificável, dentre outros fatores, pela falta de tempo, que resulta em quantidade significativa de dejetos e, consequentemente, gera problemas para as grandes cidades. Partiu-se, pois, de um problema comum a todos os seres humanos contemporaneamente para chegar a uma questão local: a existência de um aterro sanitário no município em que os alunos estão inseridos e as consequências disso para a cidade, bem como os demais problemas relacionados ao saneamento básico que os cidadãos enfrentam. 
Essa discussão desenvolveu-se permeada pela reflexão acerca das políticas públicas que acabam por responsabilizar os consumidores pela poluição e pelas ações de reparação, bem como a influência do discurso científico no cotidiano das pessoas. Além disso, o projeto contou com o apoio de profissionais de outros componentes curriculares, na tentativa de garantir um trabalho coeso e interdisciplinar.

O objetivo geral deste projeto de letramento foi, assim, promover a apropriação de conhecimentos veiculados pela língua escrita, bem como o reconhecimento e o agenciamento dos recursos linguísticos implicados nos diferentes projetos de dizer, a fim de que os alunos compreendessem criticamente o entorno onde vivem e o modo pelo qual as questões relacionadas ao plano local dialogam com os problemas globais.

A escolha desse tema tem como principal razão os problemas relacionados ao saneamento básico e à infraestrutura da cidade em que se realizou a pesquisa, especialmente no que se refere ao município em que a escola está localizada. O entorno em que a escola está situada, a moradia em que esses alunos vivem, os locais do município em que eles passam seus momentos de lazer são diretamente influenciados pelos problemas de saneamento básico e infraestrutura da cidade. Então, acreditamos que um trabalho tratando desses entornos poderia favorecer o envolvimento da turma nas ações desenvolvidas.

A partir disso, delineamos como objetivos específicos a promoção da apropriação de conhecimentos veiculados por meio da escrita que contribuíssem efetivamente para a formação dos alunos enquanto sujeitos que refletem criticamente acerca de situações de seu entorno imediato, relacionando tais questões com aspectos que se delineiam globalmente. Esperou-se, ainda, contribuir para que os alunos reconhecessem e agenciassem os diversos recursos linguísticos em usos sociais, refletindo sobre suas implicações nos projetos de dizer.

Assim, desenvolveu-se um planejamento centrado em artefatos escritos, abrindo mão, portanto, de seguir programas determinados previamente. Podemos afirmar que o princípio mais importante na elaboração do planejamento foi a inserção dos alunos em práticas sociais relevantes e, com base nisso, determinamos os textos a serem abordados nessa prática social, a fim de selecionar artefatos de determinados gêneros segundo sua relevância para o aluno e para a comunidade, dependendo, também, do sistema de atividades nas quais os sujeitos estavam inseridos.

Sob essa ancoragem, reiteramos que o eixo norteador deste projeto de letramento não foi o ensino dos gêneros do discurso em si, tampouco os conteúdos programáticos previstos em documentos parametrizadores de ensino, mas, do início ao fim, a prática social. Buscou-se, 
assim, colocar os conteúdos curriculares em favor da participação em diversos eventos de letramento e da compreensão social por parte do aluno. Isso não significou, porém, abrir mão dos conhecimentos necessários ao desenvolvimento do aluno.

Sob esta perspectiva, trabalhamos com diversos conteúdos curriculares do primeiro ano do Ensino Médio (autores contemporâneos, verbos no modo imperativo, denotação e conotação, dentre outros), bem como uma considerável variedade de gêneros (crônica, notícia, reportagem, texto de dicas, infográficos, mesa-redonda, dentre outros), ainda que as ações não tivessem como princípio organizador nenhum dos dois aspectos.

O trabalho com a seleção dos conteúdos seguiu o caminho inverso do que tradicionalmente é feito: partir do conteúdo para selecionar os textos. Ao contrário, os próprios textos deram subsídios para a discussão de determinados conteúdos, conhecimentos e recursos linguísticos. Nesse planejamento, não seguimos livros didáticos nem apostilas escolares. Porém, recorremos a gramáticas normativas e dicionários quando surgia necessidade deles durante a leitura e a produção de textos. Portanto, livros didáticos e apostilas deixaram de ser materiais essenciais para as aulas de Língua Portuguesa.

Em relação à questão da natureza e da progressão dos conteúdos abordados, os eventos presentes no projeto de letramento envolviam tanto aspectos globais quanto locais, concernentes à realidade da comunidade em que o trabalho foi desenvolvido. Por essa razão, ainda que os textos das instituições públicas de prestígio sejam os principais representantes do acervo abordado nos planejamentos, atentamos para a necessidade de incluir os textos que circulam em outras esferas, como os da intimidade doméstica, como o texto de dicas que contemplamos em nossa intervenção.

Dessa forma, organizamos as ações em dois blocos - global e local -, profundamente articulados, diversificando os objetos de leitura. Neste projeto, os alunos leram e pesquisaram anúncios, bem como escreveram comentários críticos em redes sociais, por exemplo. Práticas como essas se convertem em convite à ampliação do acervo de textos circulantes na sala de aula e contribuem, consequentemente, para a ampliação das práticas de uso da língua pelos alunos.

Para que não houvesse distanciamento (ou até mesmo ruptura) entre a escola e o universo do aluno que comprometesse o trabalho em favor da ampliação das práticas de letramento dos alunos, atentamos para a importância, como mencionamos, ter presentes as já desenvolvidas pelos estudantes, a fim de que lhes seja facultada a participação em nossos eventos de letramento, que encontrem contraporte nos eventos dos quais participam. 
É necessário ressaltar que a escolha dos textos com os quais trabalhamos neste projeto de letramento foi, assumidamente, um ato político e ideológico. Afinal, existem eventos de letramento dos quais, possivelmente, os alunos só tomam parte na escola. Se a escola não lhes facultar a participação em determinados usos da língua, outra instituição, provavelmente, não o fará.

Como principal agência de letramento (KLEIMAN, 1995), a escola é o lugar mais afeito à leitura de determinados tipos de textos. É a instituição em que se configuram modos específicos de interagir por meio da escrita, conforme os pressupostos acadêmicos. Assim concebendo, o trabalho com problemáticas pertinentes ao cotidiano dos alunos serviu, em alguma medida, de ponto de partida para a leitura de textos que, em outras esferas, que não a escolar, o aluno não teria acesso.

Também é comum a problematização acerca da forma romântica pela qual os letramentos vernaculares são abordados nos Estudos do Letramento (cf. STREET, 2003). Pode-se asseverar que essa problemática não está nos Estudos do Letramento em si, mas no modo possivelmente equivocado como este é interpretado. Portanto, a verdadeira intenção não é isolar as práticas menos prestigiadas de outras que estão fora, mantendo-as puras, mas tomá-las como ponto de partida para a apresentação de/trabalho com letramentos dominantes.

Iniciamos o projeto de letramento com um texto de linguagem simples e temática relacionada ao cotidiano, mas sem abrir mão de apresentar aos alunos um texto tipicamente alinhado a práticas de letramento dominantes. A crônica Exigências da vida moderna, de Luís Fernando Veríssimo, trata de um tema aparentemente simples, constantemente discutido no cotidiano das pessoas: a falta de tempo.

Um dos objetivos dessa primeira aula era levar os alunos a refletirem sobre o quanto as pessoas costumam atender a demandas pré-determinadas socialmente, seja por influência religiosa, da comunidade ou da ciência, desnaturalizando o processo de inserção social. Ainda nessa aula, foi possível interpretar as passagens irônicas da crônica como recurso linguístico agenciado na tentativa de convencer o leitor.

$\mathrm{Na}$ aula seguinte, trouxemos outro artefato, o texto de dicas, na tentativa de levar os alunos a compreenderem familiaridades entre a temática do tempo debatida na crônica Exigências da vida moderna e outros textos que circulam socialmente. Foi realizado um trabalho de análise linguística no seguinte sentido: identificar os verbos no modo imperativo como recurso linguístico agenciado na tentativa de aconselhar o leitor. Os alunos identificaram 
a recorrência deles, mas não sabiam classificá-los com esse nome. Inferiam a função desses verbos e identificavam suas formas, mas não os nomeavam conforme a gramática normativa.

Foi aí que recorremos à gramática para sistematizar um conhecimento que parecia, até aí, intuitivo. Afinal, não basta saber, é preciso saber dizer, ainda que isso não seja em si o foco das ações desenvolvidas. Desse modo, a nomenclatura é mais uma ferramenta no processo de aprendizagem. Por isso, tomamos o trabalho com a especificidade da linguagem/língua como um suporte às práticas de leitura e de produção textual escrita, propiciando uma reflexão ativa e consciente dos fenômenos gramaticais, textuais e discursivos em favor dos usos sociais da escrita.

Em relação às atividades de análise linguística, a preocupação era de que elas não se resumissem ao trabalho com as questões gramaticais do texto, tampouco à análise de orações soltas, sem ligação contextual, tomando o texto como mero pretexto para exercícios gramaticais.

Nas aulas seguintes, trabalhamos o texto Quanto tempo o brasileiro gasta com o smartphone?, na tentativa de levar os alunos a reconhecerem o quanto as produções humanas da esfera da ciência se colocam em nosso cotidiano de modo a conformarem as ações das pessoas e retomar o tratamento dado à temática do tempo na contemporaneidade.

Considerando as reflexões empreendidas na aula anterior, realizamos uma pesquisa em jornais e revistas, buscando identificar, em textos como propagandas, matérias jornalísticas e notícias, o paradoxo existente entre a necessidade de ganhar tempo e os inúmeros convites contemporâneos para ocupá-lo com questões fugazes. Boa parte dos textos selecionados pelos alunos era, justamente, anúncio de celulares.

A partir disso, trouxemos para a aula a música Passarinhos, interpretada pelo cantor Emicida com participação da cantora Vanessa da Mata, como uma tentativa de sintetizar a lástima humana da solidão, exacerbada em contexto como os atuais de exigências e competividade, bem como os problemas ambientais inerentes ao crescimento das grandes cidades, fazendo-o por meio de um artefato cultural associado à arte, fundamental, a nosso ver, no percurso de formação dos sujeitos.

Quando a música foi reproduzida, os alunos afirmaram que ouviram-na em outras oportunidades, mas não como objeto de estudo, ou seja, ouviram em casa, no carro, mas sem atentar para o conteúdo da música e para as possíveis críticas sociais presentes nela. Afinal, o que lemos e o modo como lemos varia conforme o lugar onde lemos: 
Sabemos que o mundo é textualizado. Leitura e escrita estão em toda parte. O que circula, portanto, na rua ou em ambientes comunitários são modos de inscrição específicos (placas, propagandas, faixas, outdoors, fachadas etc.) de grande força comunicativa e que, por isso, merecem atenção. Consumir e saber produzir os inúmeros textos que se distribuem nos mais variados contextos sociais significa não apenas ter acesso a essas práticas comunicativas mas também assumir uma forma de poder que é negada a muitos. (OLIVEIRA, 2010, p.6)

Conseguir ler a letra da música, vale destacar, não é garantia de entendê-la por completo. Isso acontece porque na música há várias referências que não podem ser compreendidas apenas com a sua leitura e que são determinantes para o entendimento mais amplo do que está sendo apresentado nela.

A aula seguinte contou com a reprodução do filme $O$ menino e o mundo ${ }^{2}$, dirigido por Alê Abreu, a partir do qual foi possível compreender a produção de sentidos empreendida também pela linguagem não verbal, por meio, entre outros aspectos, das caracterizações que, no filme, diferenciam campo e cidade.

Ao longo da reprodução do filme, os alunos já sinalizavam o entendimento de que, apesar de tratar-se de uma animação, há referências no filme que não seriam compreendidas perfeitamente pelo público infantil. O filme também sinaliza para a discussão que permearia o conjunto de ações presentes no bloco de aulas que intitulamos global, qual seja: a reflexão sobre o desenvolvimento econômico não planejado e seu impacto no meio ambiente.

Ao longo do projeto de letramento, procuramos manter a continuidade entre as aulas, estabelecendo referências com as quais os alunos tiveram contato em aulas anteriores. Essa iniciativa fez com que, a cada aula, os alunos mantivessem a sensação de que aprenderam algo significativo na aula anterior que os fez avançar para a apropriação de novos conhecimentos via participação de novos eventos de letramentos.

Por exemplo, nas primeiras aulas, apresentamos uma crônica de Luís Fernando Veríssimo, gênero que foi retomado na nona aula, com a seleção de um texto no mesmo gênero e do mesmo autor. Desse modo, quando os alunos tomaram a crônica em mãos, já estavam, de certa forma, familiarizados com aquele tipo de texto e já conheciam o autor. Espera-se, com isso, que, em outras oportunidades, os alunos reconheçam crônicas publicadas em jornais ou revistas para além da esfera escolar, sem a intervenção do professor, bem como estabeleçam relações entre o trabalhado na escola e o mundo da vida, em razão de seu envolvimento em eventos de letramentos que funcionaram em favor da ampliação das práticas de letramento.

\footnotetext{
${ }^{2} \mathrm{O}$ trailer do filme está disponível em: https://www.youtube.com/watch?v=61FP8FVUwK8
} 
O último texto compreendido pelo que intitulamos de bloco global é, assim, uma crônica, artefato trabalhado nas primeiras aulas do projeto de letramento. Nossa intenção com a escolha desse texto, como já mencionado, foi a de criar um vínculo dos alunos tanto com o gênero crônica quanto com o autor, Luís Fernando Veríssimo, de modo que eles se sentissem efetivos leitores desse tipo de texto, legítimos participantes desse tipo de eventos de letramento.

A partir disso, podemos inferir que a participação no evento anterior, leitura de crônica, contribuiu para a ampliação de práticas de letramento pela participação em eventos de letramento dessa natureza. Além disso, o percurso desenvolvido neste bloco foi providencial para introduzir as discussões mais ligadas ao bloco que intitulamos de local, sem circunscrever os alunos a tal plano, além de facultar uma visão menos ingênua e meramente opinativa sobre as questões locais.

Apesar de não serem leitores frequentes de textos da esfera jornalística, como ficou evidenciado nas entrevistas com os participantes, a notícia sobre o presidente do sindicato de hotéis de Florianópolis que responsabilizou os ambulantes pelo surto de viroses nas praias do norte da Ilha gerou indignação na turma.

A leitura dessa notícia deu início às ações do bloco que intitulados de local. Como era esperado, considerando a tradição oral em que os alunos estão imersos, essa facilidade para debater questões polêmicas oralmente não se repetiu quando foi sugerida uma produção escrita, a primeira produção textual prevista no projeto de letramento. Entretanto, ainda que com certa resistência, os alunos se sentiram mais à vontade para produzir um texto para ser publicado em um suporte que eles já conheciam: a página do jornal no Facebook.

Importa explicitar que a orientação dessa atividade não teve contornos de aferição do cumprimento da tarefa escolar exclusivamente, mas de socialização dos posicionamentos destacados via comentário crítico com os colegas do grupo. Além disso, tal atividade foi ponto de partida para que retomássemos e aprofundássemos a discussão acerca das condições de produção desse comentário crítico.

O objetivo desse conjunto de ações é, portanto, a transformação social, que se dá paulatinamente, à medida que os alunos engajam-se em eventos de letramento que contribuem para a ampliação das práticas de letramento.

$\mathrm{Na}$ aula seguinte, realizamos a leitura da reportagem Mariana: os dramas e a culpa pela tragédia. Os alunos reconheceram as semelhanças entre o texto desta aula e os lidos anteriormente, especialmente em relação ao conteúdo temático. Gerou, inclusive, a mesma indignação. 
Os alunos compreendem de modo crítico a aparente impunidade das grandes empresas, enquanto o cidadão costuma ser culpabilizado pelos problemas ambientais como acúmulo de lixo e proliferação de doenças. Afastamo-nos, portanto, de uma visão neutra do letramento e nos aproximamos de um ponto de vista mais sensível a contextos culturais específicos.

Observamos que essa prática mobilizou os alunos e fortaleceu a coerência das ações seguintes, previstas no planejamento.

Para a aula seguinte, foi planejada uma palestra com a professora de Geografia, que analisou a questão do lixo sob uma perspectiva mais ampla, debatendo saneamento básico e infraestrutura das cidades. A educadora trouxe a questão do saneamento básico sob uma perspectiva não apenas científica, mas também social, histórica e cultural.

$\mathrm{Na}$ aula seguinte à palestra, fizemos a leitura de uma notícia publicada, na mesma semana, no jornal Biguaçu em Foco. Fizemos a leitura da notícia e retomamos a discussão empreendida na aula anterior. O posicionamento crítico dos alunos era visível e bem diferente da apatia dos primeiros encontros. Nem foi preciso insistir para que falassem.

Com base na leitura da notícia, propusemos uma atividade de produção textual. Seria a produção coletiva de uma carta aberta, comentando a notícia, que seria enviada ao jornal. Durante todo esse processo, os alunos refletiam sobre o melhor modo de organizar suas opiniões no texto. Estavam preocupados com a clareza e a objetividade, mas também com a argumentação. Foi possível perceber que os alunos se mostraram mais atentos às convenções da escrita em função do objetivo pretendido.

Os alunos não esperavam que a carta fosse publicada, mas ela foi. Aliás, essa situação pode servir de incentivo a outros professores que, porventura, estejam receosos em oferecer contribuições derivadas de uma ação pedagógica a diferentes meios de publicação, a exemplo do jornal, por conta da frustração possível caso a produção não seja publicada. Quando entramos em sala com o jornal em mãos e contamos da publicação do texto, eles ficaram eufóricos, disputavam o jornal para ler o texto em meios a gritos e risadas.

A partir da mudança de perspectiva dos alunos ao longo do processo, reconhecemos o caráter transformador do projeto de letramento. É possível perceber que, agora, os alunos se veem aptos a pensar sobre notícias publicadas em jornais e opinar a respeito delas usando a linguagem escrita. Portanto, fica evidente que o desenvolvimento de práticas converge com a participação nesse tipo de evento de letramento e que houve um passo em direção à função social emancipadora da escrita. 
Ao final da implementação do projeto, podemos afirmar que, a despeito de todas as constrições institucionais e do histórico de fracasso escolar dos alunos, é possível desenvolver ações de ensino que ampliem as práticas de uso da língua desses sujeitos e facultem imersão mais efetiva deles na cultura escrita.

Para isso, no trabalho com alunos que têm uma história de dificuldades de aprendizagem no contexto escolar, o(s) professor(es) não deve(m) abrir mão da responsabilidade de levar a termo um planejamento teoricamente ancorado, tampouco da intervenção pedagógica. Pelo contrário, deve-se atentar para a realidade exclusão em instituições orientadas para a inclusão, a exemplo da escola, que muitas vezes negam aos alunos o direito de permanecerem aprendendo, porque focalizam suas ações na formação pragmática, orientada para a inserção social miúda, periférica e marginal e secundarizam a centralidade que a escrita precisa ter, dada a centralidade que também ela, a escrita, ocupa neste modo de organização social.

\section{Considerações finais}

O presente estudo focalizou a imersão na cultura escrita por alunos de $1^{\circ}$ ano de Ensino Médio oriundos de um programa ocupado com equiparação idade/série e a continuidade escolar desse processo. Por isso, descrevemos analiticamente as implicações de um processo de ensino para a participação em eventos de letramento e para a ampliação das práticas de letramento e imersão na cultura escrita desses alunos.

À luz dessa focalização, filiamo-nos teoricamente aos Estudos do Letramento, contemplando conceitos de práticas e eventos de letramento, modelos autônomo ideológico de letramento, bem como as relações entre letramentos dominantes e vernaculares e os universos global e local, sempre refletindo acerca das implicações desses conceitos para o ensino escolar.

Nessa tentativa de entendimento, desenvolvemos ações com foco na participação em eventos de letramento, movidas pelo compromisso de contribuir para o processo de imersão dos alunos na cultura escrita, organizadas em um projeto de letramento (KLEIMAN, 2000). Essas ações visaram contribuir para a ampliação dos usos sociais da escrita pela reflexão sobre a relação entre a sociedade, natureza e homem na contemporaneidade, tendo como norte a resposta à seguinte questão de pesquisa: Como empreender um processo de caráter escolar que faculte participação em eventos de letramento e a ampliação das práticas de letramento e imersão na cultura escrita por alunos oriundos de um programa de correção de fluxo? 
Durante a implementação do projeto de letramento em tela, foi possível compreender o modo pelo qual as práticas de letramento reverberaram na participação nos eventos de letramento propostos em sala de aula. Também foi possível reconhecer, sobremaneira, as contribuições do processo realizado na pesquisa para nossa formação docente ou, por outra, como agente de letramento. Apesar das constrições institucionais, descritas neste estudo, entendemos que é possível desenvolver ações de ensino comprometidas com a ampliação das práticas de uso da língua e promover mudanças dentro e fora do contexto escolar ao mesmo tempo em que lutamos por condições mais dignas para realizarmos nosso trabalho.

Essa perspectiva de trabalho com a leitura e a escrita se afasta das práticas aportadas no modelo autônomo de letramento. Pelo contrário, evitamos a dissociação das dimensões social e política nas práticas de leitura e escrita e problematizamos a responsabilização do aluno pela situação de fracasso escolar. Trabalhamos a partir do reconhecimento de que a escola tem funções que só ela, principal agência de letramento, pode desempenhar como espaço de transformação social e ressignificação de subjetividades, e não de neutralidade e uniformidade.

Desse modo, reconhecemos que o domínio de instrumentos culturais e o conhecimento sistematizado não retiram do letramento as suas implicações ideológicas, mas consideramos a heterogeneidade da escola e evitamos a hierarquização entre os modos de lidar com a escrita, na tentativa de relacionar diretamente leitura e escrita às práticas sociais.

Cabe destacar, finalmente, o que nos parece imperativo nos trabalhos via projetos de letramento: a prática social como ponto de partida e de chegada. Essa perspectiva de trabalho inviabiliza, na origem, um trabalho alinhado ao ensino tradicional e ao relativismo, objeto de crítica contemporaneamente justamente em razão do esvaziamento do papel da escola.

\section{Referências}

BARTON, David. Literacy: an introduction to the ecology of written language. Oxford: Blackweell, 2010 [1994].

BARTON, David; HAMILTON, Mary. Local literacies: reading and writing in one community. Londres: Routledge, 1998.

BARTON, David; HAMILTON, Mary; IVANIC, Roz (Org.) Situated literacies. London: Routledge, 2000a

HAMILTON, Mary. Expanding the new literacy studies: using photographs to explore literacy as social practice. In: BARTON, D.; HAMILTON, M.; IVANIC, R. (Orgs.). Situated literacies. London: Routledge, 2000. 
KLEIMAN, Angela B. (Org.). Os significados do letramento: uma nova perspectiva sobre a prática da escrita. Campinas, SP: Mercado dos Letras, 2001 [1995].

KLEIMAN, A. (Org.). O ensino e a formação do professor: alfabetização de jovens e adultos. Porto Alegre: Artes Médicas, 2000.

STREET, Brian. Literacy in theory and practice. Cambridge: CUP, 1984.

Abordagens alternativas ao letramento e desenvolvimento. Teleconferência

Brasil sobre o letramento, outubro de 2003.

Recebido em 31 de maio de 2018. Aceito em 10 de outubro de 2018. 